\title{
SAEB E PNLD: DISSONÂNCIAS E IMPLICAÇõES DAS AVALIAÇÕES DE LARGA ESCALA NO CONTEXTO EDUCACIONAL BRASILEIRO
}

\author{
SAEB AND PNLD: DISSONANCES AND IMPLICATIONS OF LARGE-SCALE \\ EVALUATIONS IN BRAZILIAN EDUCATIONAL CONTEXT
}

DOI: 10.23926/RPD.2526-2149.2020.v5.n2.p673-699.id724

\author{
Pedro Franco de Sá \\ Doutor em Educação \\ (UFRN) \\ Docente na Universidade do \\ Estado do Pará (UEPA) \\ Docente dos Programa de \\ Pós Graduação em Educação \\ (UEPA), Profissional em \\ Ensino de Matemática \\ (UEPA) e Educação em \\ Ciências e Matemática \\ (UFMT/UFPA/UEA) \\ pedro.sa@uepa.br
}

\section{Maria de Lourdes \\ Silva Santos}

Doutora em Educação

(PUC/Rio)

Docente na Universidade do Estado do Pará (UEPA)

2011malu.melo@gmail.com

\section{Andrea da Silva \\ Marques Ribeiro}

Doutora em Linguística

Aplicada e Estudos da

Linguagem (PUC/SP)

Docente na Universidade do

Estado do Rio de Janeiro

(UERJ)

Docente do Programa de

Pós-Graduação Profissional

de Ensino e Educação Básica

(UERJ)

andrea.marques@gmail.com
Resumo: Este trabalho apresenta os resultados de uma investigação que teve como objetivo analisar o diálogo referencial entre o Sistema de Avaliação da Educação Básica (SAEB) e o Programa Nacional do Livro Didático (PNLD). A produção das informações se deu por meio da análise de documentos do SAEB, na busca de referências sobre o PNLD e de documentos do PNLD buscando referências ao SAEB. Os resultados indicam que o diálogo entre as duas políticas é praticamente nulo e que provoca um efeito drástico da avaliação educacional brasileira, o que leva ao questionamento dos resultados que o SAEB produz acerca da Educação Brasileira. As análises evidenciam a existência de um ciclo de fracasso como produto da falta de diálogo entre as referidas políticas.

Palavras-chave: Avaliação Educacional. Avaliação de Larga Escala. Diálogo entre SAEB e PNLD

\begin{abstract}
This paper presents the results of a research that aimed at analyzing referential dialogue between The National Basic Education Assessment System (SAEB) and the National Textbook Program (PNLD). Data analysis was based on PNLD references on the documents of SAEB as well as SAEB references on PNLD documents. The results indicate that there is almost no dialogue between the two public policies and it can cause drastic effects in the assessment of Brazilian education, which leads to questioning the results concerning Brazilian Education produced by SAEB. Also, in the analysis, a cycle of failure is highlighted as a product of the lack of dialogue between such policies.
\end{abstract}

Keywords: Educational assessment. Larger scale rating. Dialogue between SAEB and PNLD 


\section{INTRODUÇÃO}

A avaliação Educacional no Brasil tem sido um tema recorrente nos meios de comunicação social e nos debates acadêmicos. Na mídia, ela tem sido apresentada como uma tentativa do governo federal junto com os entes federados de desenvolver uma avaliação sistemática da qualidade da educação brasileira e que tem produzido resultados com base em indicadores de desempenho de estudantes a partir de exames em Língua Portuguesa e Matemática de natureza de múltipla escolha. Os meios de comunicação social têm sistematicamente apresentado preocupação a respeito da qualidade da educação brasileira a partir da divulgação destes resultados.

A motivação para a realização do estudo, que tem seus resultados apresentados neste texto, gerou-se a partir de inquietações sentidas diante das repetidas apresentações dos idênticos resultados da avaliação da educação básica brasileira, apesar de todo o esforço que presenciamos de colegas docentes do referido nível de ensino, na busca de elevar o desempenho de seus estudantes nas avaliações de larga escala.

Outra fonte de motivação decorreu de pesquisas relacionadas a avaliação em larga escala como a de Aragão, Ferreira e Santos (2013) que levantaram questões e reflexões sobre o processo de tal avaliação, onde destaca que é importante incorporar análise do trabalho pedagógico realizado em sala de aula. Outro trabalho que fortaleceu a motivação foi o de Vianna (2014) quando afirmou que a análise do livro didático devia ser uma fonte de informação para avaliação da educação, devido ao fato que o referido material didático se tornou um ponto comum do trabalho pedagógico de todas as escolas públicas, muitas vezes sendo o definidor do currículo e o único material acessível.

Mais recentemente a leitura de Vinha e Laros (2018) reforçou nossa motivação por apresentarem resultados referentes aos dados ausentes das avaliações educacionais e as possibilidades de justificativa para a ausência.

Esta inquietação gerou as seguintes questões norteadoras:

(a) O que já foi realizado para superar os resultados da avaliação de larga escala?

(b) Por que apesar de todos os esforços envidados, os resultados da avaliação de larga escala são sempre muito próximos em todos os sistemas de ensino do Brasil?

(c) Os resultados da avaliação de larga escala representam o que é desenvolvido nas unidades escolares?

(d) Os resultados dos exames de proficiência refletem os conhecimentos dos estudantes?

(e) O que provoca essa estabilização dos resultados da avaliação de larga escala? 
Devido a nossa vasta experiência anterior como docentes da Educação Básica, a busca de respostas para as questões supra apresentadas levou a realização de uma pesquisa que teve o objetivo avaliar o diálogo entre o SAEB e o PNLD e as suas consequências. Tal objetivo é fruto de nossa certeza da forte influência do livro didático cotidianamente no processo pedagógico realizado nas escolas, em particular nas disciplinas Língua Portuguesa e Matemática, principalmente nas escolas da rede pública.

\section{ESTUDOS RELACIONADOS}

Horta Neto (2013) apresenta os efeitos de uma pesquisa que objetivou analisar o desenvolvimento dos testes aplicados, pela União e pelos Estados de Minas Gerais e São Paulo aos alunos do ensino Fundamental de 1990 a 2012, buscando identificar como os resultados obtidos estão sendo utilizados pelas políticas educacionais. Os resultados obtidos e analisados permitiram o autor concluir que

[...] os testes tem sido utilizados não como um instrumento para avaliar os sistemas educacionais e auxiliar no processo de aprendizagem dos alunos, mas sim como um instrumento de regulação do trabalho realizado pela escola e por seus profissionais, e, assim seus resultados não têm influenciado as políticas educacionais. (HORTA NETO, 2013, p. 8)

Montavani (2009) apresenta os resultados de uma pesquisa que objetivou, a partir de levantamento documental, analisar a importância da avaliação do livro didático realizadas pelos programas de governo e o impacto desse processo na qualidade de ensino na escola pública. A pesquisa utilizou informações referentes ao período de 1995 a 2005. A pesquisadora afirmou, com base nas análises realizadas, que "o ensino brasileiro não sentiu os reflexos da melhoria dos materiais didáticos distribuídos aos estudantes da rede pública" (MONTAVANI, 2009, p. 85). Tal afirmação foi justificada pelo fato de que o desempenho da escola pública na avaliação externa não sofreu influência positiva do aperfeiçoamento do processo de avaliação dos livros didáticos por parte dos órgãos governamentais. O resultado de Montavani (2009) mostra necessidade de atenção especial ao livro didático quando da realização da avaliação de larga escala brasileira.

Em Sampaio (2014), são encontrados os resultados de um estudo cujo objetivo foi identificar variáveis associadas ao estudante, à turma e ao professor, os quais predizem o desempenho escolar dos alunos na Prova Brasil por meio de uma análise multinível. As informações foram produzidas a partir dos bancos de dados do Instituto Nacional de Estudos e Pesquisas Educacionais Anísio Teixeira (INEP). Durante as análises dos dados, foi realizada a Modelagem Multinível dos Questionários Socioeconômicos sobre o Desempenho Escolar na Prova Brasil do 
ano de 2011, a partir da proficiência em Língua Portuguesa. Primeiramente, foi estimado o ajuste do modelo nulo e de três níveis. Para o modelo de três níveis: o Efeito-Escola, Efeito-Turma e Efeito-Aluno. Os resultados da análise estão sintetizados no Quadro 01 a seguir.

Quadro 1 - Síntese dos resultados da pesquisa de Sampaio (2014)

\begin{tabular}{|c|c|c|c|}
\hline Efeito & $\begin{array}{c}\text { Natureza das Variáveis } \\
\text { consideradas }\end{array}$ & $\begin{array}{c}\text { Variável de maior peso } \\
\text { explicativo do desempenho }\end{array}$ & Conclusões \\
\hline Aluno & $\begin{array}{l}\text { 1) Caracterização sócio } \\
\text { demográfica do aluno. } \\
\text { 2) Capital social. } \\
\text { 3) Capital cultural. } \\
\text { 4) Motivação e autoestima. } \\
\text { 5) Práticas de estudo. } \\
\text { 6) Trajetória escolar. }\end{array}$ & $\begin{array}{ll}- & \text { Gênero } \\
\text { - } & \text { Raça } \\
\text { Nivel de escolaridade dos } \\
\text { pais. } \\
\text { - } \\
\text { Realizar atividades } \\
\text { laborais. }\end{array}$ & $\begin{array}{l}\text { 1)Em relação ao gênero, as mulheres } \\
\text { apresentaram melhor desempenho em } \\
\text { Língua Portuguesa que os homens e os } \\
\text { homens apresentaram melhor } \\
\text { desempenho que as mulheres em } \\
\text { Matemática; } \\
\text { 2) No que concerne a raça, os brancos } \\
\text { apresentaram um melhor desempenho do } \\
\text { que os negros; } \\
\text { 3) Em termos de nível de escolaridade } \\
\text { dos pais, os pais com Ensino Médio } \\
\text { concluído refletem, positivamente, no } \\
\text { desempenho escolar dos estudantes; } \\
\text { 4) O fato de realizar atividades laborais } \\
\text { (domésticas ou remuneradas) apresenta } \\
\text { impacto negativo no desempenho dos } \\
\text { alunos. } \\
\text { 5) As variáveis referentes ao aluno se } \\
\text { destacaram como importantes, uma vez } \\
\text { que, todas as que foram testadas, } \\
\text { apresentaram-se como significativas. }\end{array}$ \\
\hline Turma & $\begin{array}{l}\text { 1) Gênero. } \\
\text { 2) Idade do Professor. } \\
\text { 3) Raça. } \\
\text { 4) Nível de Escolaridade } \\
\text { do Professor. } \\
\text { 5) Formação } \\
\text { Complementar do } \\
\text { Professor. } \\
\text { 6) Remuneração docente } \\
\text { 7) Tempo de serviço } \\
\text { docente. } \\
\text { 8) Prática Pedagógica. }\end{array}$ & $\begin{array}{ll}\text { - } & \text { Escolaridade do professor. } \\
\text { - } & \text { Experiência do professor. } \\
\text { - } & \text { Salário do professor. }\end{array}$ & $\begin{array}{l}\text { 1) Há um crescimento no desempenho } \\
\text { dos alunos, ao passo que os professores } \\
\text { vão ganhando experiência; } \\
\text { 2) Os professores que têm mais de quinze } \\
\text { anos de serviço, são os que mais } \\
\text { influenciam seus alunos. } \\
\text { 3) Os professores que ensinam em quatro } \\
\text { ou mais escolas, são aqueles que tendem } \\
\text { a influenciar mais os alunos, quando } \\
\text { comparados aos professores que somente } \\
\text { ensinam em uma única escola. } \\
\text { 4) A remuneração docente influencia } \\
\text { positivamente seus estudantes. }\end{array}$ \\
\hline Escola & $\begin{array}{l}\text { 1) Infraestrutura } \\
\text { 2) Segurança } \\
\text { 3) Recursos Tecnológicos } \\
\text { 4) Áreas Públicas } \\
\text { 6) Suporte Escolar } \\
\text { 8) Problemas Escolares } \\
\text { 9) Atividade } \\
\text { Extracurricular } \\
\text { 10) Financiamento } \\
\text { 11) Violência }\end{array}$ & $\begin{array}{ll}- & \text { Suporte escolar } \\
- & \text { Programa de reforço de } \\
& \text { taxa de abandono }\end{array}$ & $\begin{array}{l}\text { 1) As variáveis relacionadas à } \\
\text { infraestrutura da escola, não } \\
\text { apresentaram um peso tão relevante } \\
\text { 2) As variáveis do Fator-Escola não } \\
\text { apresentaram grande poder explicativo } \\
\text { sobre o desempenho. }\end{array}$ \\
\hline
\end{tabular}

Fonte: Sampaio (2014).

A pesquisadora, em função do percentual de variância, concluiu que as variáveis associadas ao Efeito-Escola explicam melhor o desempenho escolar do que as variáveis do 
Efeito-Turma. Além disso, também considerou como limitantes da pesquisa, o fato de não ter podido avaliar variáveis de natureza psicológica devido as mesmas não constarem do questionário.

Os resultados e conclusões obtidos produzidos pela investigação mostram que ainda há espaço para novas pesquisas sobre fatores que influenciam fortemente no desempenho em avaliação em larga escala, incluindo a análise de material didático utilizado, em particular o livro didático, como foi registrado por Vianna (2014).

Bauer et al (2015) apresentam os resultados de uma pesquisa que teve como objetivo mapear e caracterizar iniciativas relacionadas às avaliações em larga escala em desenvolvimento nos municípios brasileiros. $\mathrm{O}$ estudo foi realizado por meio de uma consulta via questionário eletrônico a 4.309 municípios brasileiros, que correspondeu a 77,4\% dos municípios, sobre os usos dos resultados das avaliações, tanto federais como estaduais e municipais, na gestão educacional dos municípios. Os resultados obtidos indicam que os municípios que participaram de pesquisa tiveram iniciativas variadas em relação aos resultados da avaliação de larga escala. O Quadro 2 a seguir sintetiza os resultados produzidos pelos pesquisadores.

Quadro 2 - Iniciativas dos municípios a partir dos resultados da avaliação em larga escala

\begin{tabular}{|c|c|c|}
\hline $\begin{array}{l}\text { Natureza da } \\
\text { iniciativa }\end{array}$ & Ação & $\begin{array}{l}\text { \% de municípios que } \\
\text { realizaram a ação }\end{array}$ \\
\hline \multirow{3}{*}{$\begin{array}{l}\text { Mobilização das } \\
\text { escolas }\end{array}$} & Motivar as escolas a buscarem melhores resultados. & 91,3 \\
\hline & Estimular as escolas a discutirem os resultados obtidos. & 88,0 \\
\hline & $\begin{array}{l}\text { Propor que as escolas produzam relatório explicativo dos } \\
\text { resultados obtidos }\end{array}$ & 47,0 \\
\hline \multirow{8}{*}{$\begin{array}{c}\text { Desenvolvimento de } \\
\text { programas } \\
\text { educacionais das } \\
\text { secretarias } \\
\text { Municipais }\end{array}$} & Avaliar programas e ações desenvolvidos pela Secretaria. & 79,2 \\
\hline & Reestruturar o currículo das escolas. & 72,7 \\
\hline & Desenvolver material didático. & 64,1 \\
\hline & Reformular o Plano Municipal de Educação & 61,5 \\
\hline & Comprar material curricular estruturado e/ou apostilado. & 36,7 \\
\hline & Dar algum prêmio aos alunos (computador, viagem, etc.) & 13,3 \\
\hline & $\begin{array}{l}\text { Dar algum prêmio às escolas (computadores, recursos } \\
\text { financeiros, etc.). }\end{array}$ & 9,5 \\
\hline & Oferecer bônus salarial aos profissionais das escolas. & 6,3 \\
\hline \multirow{5}{*}{$\begin{array}{l}\text { Monitoramento da } \\
\text { rede de ensino }\end{array}$} & Identificar carências das escolas da rede. & 84,5 \\
\hline & Propor intervenções diferenciadas nas escolas. & 84 \\
\hline & Diagnosticar desigualdades entre as escolas da rede. & 62,9 \\
\hline & $\begin{array}{l}\text { Estabelecer metas de desempenho para as escolas, além } \\
\text { daquelas fixadas pelo Ideb. }\end{array}$ & 62,7 \\
\hline & Remanejar alunos entre as escolas da rede. & 11,9 \\
\hline \multirow{5}{*}{$\begin{array}{l}\text { Apoio da gestão de } \\
\text { pessoal }\end{array}$} & Planejar a formação continuada dos profissionais da rede. & 84,1 \\
\hline & Remanejar professores entre as escolas da rede. & 21,4 \\
\hline & Remanejar gestores entre as escolas da rede. & 11,4 \\
\hline & Demitir gestores escolares. & 6,0 \\
\hline & $\begin{array}{l}\text { Fornecer informações sobre as escolas para as famílias e a } \\
\text { comunidade escolar. }\end{array}$ & 85,1 \\
\hline
\end{tabular}




\begin{tabular}{|c|l|c|}
\hline $\begin{array}{c}\text { Divulgação de } \\
\text { informações para } \\
\text { diferentes públicos }\end{array}$ & $\begin{array}{l}\text { Colocar os resultados em uma placa visível na frente da } \\
\text { escola. }\end{array}$ & 22,6 \\
\hline
\end{tabular}

Fonte: Bauer et al (2015).

Os resultados apontados por Bauer et al (2017) indicam que a avaliação em larga escala mobilizou os sistemas educacionais dos municípios brasileiros. Infelizmente os resultados divulgados pelo INEP referentes a avaliação em questão indicam que ainda há algo muito importante a ser realizado para que se alcance os resultados desejados.

Em Quartieri et al (2016) temos os resultados de uma análise das questões dos três livros didáticos, do $5^{\circ}$ ano, com base nos descritores enunciados nos Temas das matrizes de referências da Prova Brasil e de uma comparação entre os exercícios encontrados nos livros e os apresentados na avaliação.

Uma das conclusões resultantes da pesquisa de Quartieri et al (2016) é que:

A investigação efetivada também permitiu verificar que existe diferença em relação ao tipo de questões desenvolvidas. Todas as questões da Prova Brasil apresentam opções de respostas (múltipla escolha), enquanto que naquelas dos livros analisados são poucas. Os alunos quando se deparam com essas questões acabam se sentindo despreparados, pois pouco é o contato que com elas possuem em suas atividades em sala de aula que, na maioria das vezes, são baseadas nos livros didáticos. (Quartieri et al, 2016, p. 621, grifos nossos)

Com relação a avaliação a situação não é recente, há quase duas décadas Gatti (2003) quando apresentou os resultados de estudos sobre o processo de avaliação em sala de aula e aludiu que:

\begin{abstract}
$\mathrm{Na}$ literatura sobre a questão [avaliação da aprendizagem] encontramos aspectos sugestivos que ajudam na reflexão sobre a condução de processos avaliativos em sala de aula. Nesses trabalhos verificam-se alguns elementos constantes, assim, por exemplo, em depoimentos de alunos encontra-se com frequência que eles nem sempre percebem como o professor concebe a avaliação e qual seu papel na aula, para além de "dar uma nota". A maioria dos estudos (ver referências bibliográficas) mostra também que alto percentual dos alunos não consegue explicitar os critérios das "notas" que seus professores atribuem. Colocam, também, que questões com palavras vagas ou questões excessivamente detalhadas ou complexas levam à confusão e, como resultado, eles, alunos, não podem mostrar o que sabem sobre a matéria, mas sim, quanto eles são bons em tentar compreender - adivinhar - o que o professor quer. Isto vale tanto para questões abertas, quanto para itens fechados, nos quais têm que entender o que é pedido pelo professor na formulação do item e também o que cada alternativa quer dizer. É frequente, nestes estudos, a observação de que o professor sempre pode "pegar" os alunos, mesmo com testes, basta que faça questões capciosas ou ambíguas ou com alternativas confusas. (Gatti,2003, p.101, grifos nossos).
\end{abstract}

O comentário anterior de Gatti (2003) evidencia a necessidade de um alinhamento entre o trabalho desenvolvido em sala de aula e as práticas avaliativas adotadas pelo docente. Também fica claro que o processo de avaliação pode sofrer influências negativas sobre o desempenho dos avaliados por inadequações do processo avaliativo desenvolvido. 
Sobre a utilização de provas como instrumento de avaliação Gatti (2003) recomenda:

$\underline{\text { Se o professor vai utilizar um tipo de prova com que os alunos não estão }}$ familiarizados, deve trabalhar com eles em exemplos dos tipos de questões que vai usar (evidentemente com outro conteúdo). Com isto, a prova do aluno dará ao professor uma ideia de quanto ele sabe sobre o conteúdo da questão e não quanto ele sabe lidar com um certo tipo de questão ou não. Isto porque, muitas vezes, o aluno não apresenta um bom desempenho na prova, não porque não domine nada do conteúdo da matéria, mas porque não entendeu como lidar com o tipo de questão proposta pelo professor. (Gatti,2003, p.103104 , grifos nossos).

Neste comentário, Gatti explicita a necessidade dos estudantes quando avaliados por meio de provas de que estas devem conter questões que os discentes tenham experiência quanto ao formato das mesmas ao serem avaliados. Do contrário, o resultado poderá não informar muito sobre o conhecimento do conteúdo trabalhado e sim o quanto os avaliados são capazes de lidar com o tipo de questão proposta no instrumento avaliativo. Uma pergunta que surge é a seguinte: o instrumento avaliativo utilizado na Prova Brasil atende a recomendação de Gatti (2003) relativo aos tipos de itens utilizados?

Souza (2017) apresenta os resultados de uma pesquisa que objetivou identificar as características das escolas públicas brasileiras com desempenho elevado na prova do ENEM. Após a análise das informações produzidas a partir da observação em loco de dez escolas, a pesquisadora concluiu que entre os fatores analisados os seguintes eram os únicos comuns a todas as escolas analisadas:

1) A realização toda semana de um simulado com questões do tipo ENEM;

2) A realização de sessões de resolução de todas as questões dos livros didáticos que sempre continham questões do tipo ENEM.

Esse resultado nos chamou ainda mais a atenção para necessidade de analisar os livros didáticos como fator influenciador do desempenho nas avaliações de larga escala. Valendo ressaltar que a estratégia utilizada pelas escolas é a mesma adotada pelos cursos preparatórios para concursos.

Horta Neto (2014) classificou as 2.387 matérias relacionadas as avaliações de larga escala coletadas no período entre 10 de janeiro de 2009 e 11 de outubro de 2012, utilizando a ferramenta "Alertas do Google" nos seguintes grupos: "Avaliações" com 1.553 registros, "Julgamento do resultado obtido" com 346, "Responsável pelo resultado obtido" com 345 e "Preparação para os testes" com 143 notícias. Além disso, o pesquisador destacou que no grupo de notícias classificadas por "Responsável pelo resultado", 169 das notícias apresentam o corpo docente como o responsável pelo resultado obtido nas avaliações. Isto mostrou que no período 
considerado, quando a notícia buscou apresentar responsáveis pelos resultados da avaliação em larga escala o professor foi responsabilizado em 169 das notícias o que indica que na categoria em questão mais de $50 \%$ das notícias atribuíam a culpa dos resultados obtidos aos docentes.

\section{Metodologia}

A produção das informações ocorreu por meio das seguintes etapas: (a) levantamento de documentos do SAEB, (b) levantamento de documentos do PNLD, (c) análise de documentos do SAEB, (d) análise de documentos do PNLD, (e) sistematização das informações e (f) cruzamentos dos resultados.

A etapa do levantamento de documentos do SAEB ocorreu por meio da busca na página do INEP que contém informações sobre o SAEB visando as seguintes informações: histórico, base legal, objetivos do SAEB e referências diretas ou indiretas ao PNLD. Também foram levantados os seguintes documentos do SAEB: questionário do Estudante, questionário do Professor, questionário do Diretor, Matriz de referência do $5^{\mathrm{a}}$ ano de Língua Portuguesa e Matemática, Matriz de referência do $9^{\mathrm{a}}$ ano de Língua Portuguesa e Matemática, Matriz de referência do $3^{\mathrm{a}}$ ano de Língua Portuguesa e Matemática, Cartilha SAEB 2017 e Prova brasil 2013.

A etapa do levantamento de documentos do PNLD se deu por meio de pesquisa na página do FNDE/PNLD a procura dos seguintes dados: edital do PNLD, de 2005 até 2020; Guia do Livro Didático, de 2005 até 2016 e Legislação do PNLD, visando as seguintes informações: histórico, objetivos do PNLD e referências diretas ou indiretas ao SAEB, Prova Brasil ou Avaliação de Larga Escala.

A análise de documentos do SAEB ocorreu por meio da busca nos documentos levantados de referências diretas ou indiretas ao PNLD e Livro Didático.

A análise de documentos do PNLD se deu por meio da busca nos documentos levantados sobre o PNLD de referências a Avaliação de Larga Escala, SAEB, Prova Brasil, Descritores da Prova Brasil, Escala de Proficiência da Prova Brasil e Questões Tipo Prova Brasil.

A etapa de sistematização das informações produziu informações referentes aos objetivos de cada política educacional em questão, incluindo: instrumentos, metodologia de ação e produtos. 
A etapa do cruzamento dos resultados materializou-se em um quadro contendo o grau de relação entre cada política, o nível de diálogo entre as mesmas com suas respectivas justificativas.

\section{Resultados E ANÁliseS}

Para analisar o diálogo entre o SAEB e o PNLD buscamos informações referentes a relação entre os seguintes itens das duas políticas nos documentos analisados: Objetivos, Órgão responsável, Público alvo, Período de existência, Produto e Base teórica.

Os itens foram classificados em: relacionados e não relacionados.

Dois itens foram considerados relacionados quando os mesmos apresentavam aspectos comuns.

Dois itens foram considerados não relacionados quando os mesmos não apresentavam aspectos comuns.

Quadro 03:

Quadro 3 - Relação entre SAEB e PNLD

\begin{tabular}{|c|c|c|c|c|}
\hline Item & SAEB & PNLD & Relação & Justificativa \\
\hline Objetivo(s) & $\begin{array}{l}\text { 1)Oferecer subsídios à } \\
\text { formulação, } \\
\text { reformulação e } \\
\text { monitoramento de } \\
\text { políticas públicas e } \\
\text { programas de } \\
\text { intervenção ajustados às } \\
\text { necessidades } \\
\text { diagnosticadas nas áreas } \\
\text { e etapas de ensino } \\
\text { avaliadas; } \\
\text { 2) Identificar os } \\
\text { problemas } \\
\text { diferenças regionais do } \\
\text { ensino; } \\
\text { 3)Produzir informações } \\
\text { sobre os fatores do } \\
\text { contexto } \\
\text { socioeconômico, } \\
\text { cultural e escolar que } \\
\text { influenciam } \\
\text { desempenho dos alunos; } \\
\text { 4) Proporcionar aos } \\
\text { agentes educacionais e à } \\
\text { sociedade uma visão } \\
\text { clara dos resultados dos } \\
\text { processos de ensino e } \\
\text { aprendizagem e das } \\
\text { condições em que são } \\
\text { desenvolvidos e } \\
\text { de competência técnica } \\
\text { e científica na área de }\end{array}$ & 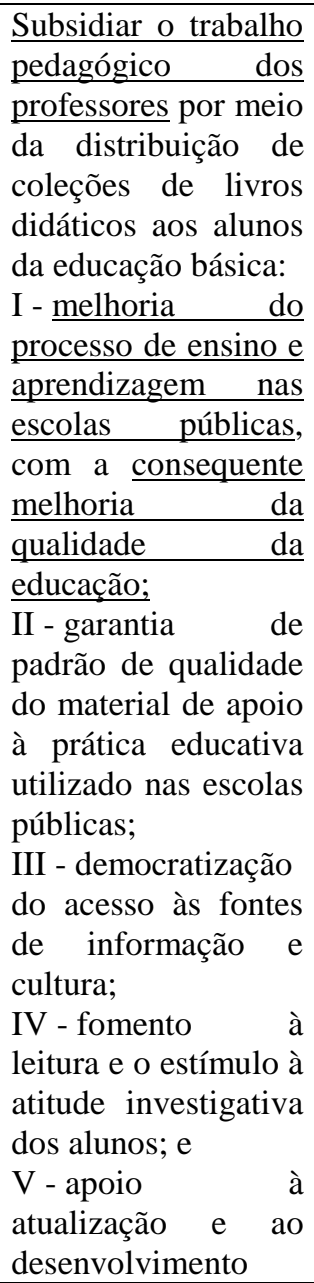 & Relacionados & $\begin{array}{l}\text { Ambas as } \\
\text { políticas têm } \\
\text { como objetivo a } \\
\text { busca do } \\
\text { aperfeiçoament } \\
\text { o da educação } \\
\text { brasileira. }\end{array}$ \\
\hline
\end{tabular}




\begin{tabular}{|c|c|c|c|c|}
\hline & $\begin{array}{l}\text { avaliação educacional, } \\
\text { ativando o intercâmbio } \\
\text { entre instituições } \\
\text { educacionais de ensino } \\
\text { e pesquisa. }\end{array}$ & $\begin{array}{l}\text { profissional do } \\
\text { professor. }\end{array}$ & & \\
\hline $\begin{array}{l}\text { Órgão } \\
\text { responsável }\end{array}$ & INEP/MEC & FNDE/MEC & relacionados & $\begin{array}{l}\text { As políticas tem } \\
\text { com o órgãos } \\
\text { responsáveis o } \\
\text { INEP e FNDE } \\
\text { são ligados ao } \\
\text { MEC. }\end{array}$ \\
\hline Público alvo & $\begin{array}{l}\text { Sistema de gestão } \\
\text { educacional }\end{array}$ & $\begin{array}{l}\text { Estudantes } \\
\text { professores dos } \\
\text { ensinos fundamental } \\
\text { e médio }\end{array}$ & Relacionados & $\begin{array}{l}\text { Tanto o SAEB } \\
\text { quanto o PNLD } \\
\text { têm como } \\
\text { públicos alvos } \\
\text { professores e } \\
\text { estudantes do } \\
\text { sistema público } \\
\text { de ensino } \\
\text { brasileiro. }\end{array}$ \\
\hline $\begin{array}{l}\text { Período de } \\
\text { existência }\end{array}$ & $\begin{array}{l}\text { Desde } 1990 \text { em } 2005 \text { foi } \\
\text { reestruturado. }\end{array}$ & $\begin{array}{l}\text { Desde } 1929 \text { surge o } \\
\text { INL e em } 1985 \text { surge } \\
\text { o PNLD. }\end{array}$ & Relacionados & $\begin{array}{l}\text { O SAEB surgiu } \\
\text { quando PNLD } \\
\text { já existia há } \\
\text { pelo menos } \\
\text { cinco anos. } \\
\text { Desse modo são } \\
\text { contemporâneo } \\
\text { s. }\end{array}$ \\
\hline Produto & $\begin{array}{l}\text { Resultados de } \\
\text { desempenho em testes; } \\
\text { Resultados de contexto. }\end{array}$ & $\begin{array}{l}\text { Guia do Livro } \\
\text { Didático }\end{array}$ & Relacionados & $\begin{array}{l}\text { Os produtos são } \\
\text { relacionados ao } \\
\text { fazer } \\
\text { pedagógico das } \\
\text { escolas. }\end{array}$ \\
\hline Base teórica & $\begin{array}{l}\text { Teoria da Resposta ao } \\
\text { Item. }\end{array}$ & $\begin{array}{lll}\text { Função do livro } \\
\text { didático. }\end{array}$ & Não relacionadas & $\begin{array}{lr}\text { As } & \text { bases } \\
\text { teóricas } & \text { não } \\
\text { tem interseção. }\end{array}$ \\
\hline
\end{tabular}

Fonte: Site do PNLD e do SAEB.

A análise do quadro 03 mostra que o PNLD e SAEB são políticas relacionadas devidos seus objetivos, órgãos responsáveis, público alvo, período de existência e produto envolvidos estarem em consonância. Os objetivos apresentam uma interface geral voltada para a melhoria da educação brasileira e os órgãos responsáveis respondem ao MEC com público-alvo os professores e estudantes das escolas públicas no Brasil. Tanto o PNLD quanto o SAEB apresentam produtos finais que são utilizados direta e indiretamente pelos atores principais da escola: estudantes e professores. O PNLD tem como um de seus produtos um Guia do Livro Didático que serve de instrumento para balizar as escolhas dos professores no que concerne o livro didático a ser usado nas aulas com os estudantes, o que impacta diretamente o fazer pedagógico. O SAEB, por sua vez, tem como produto final a apresentação de resultados relativos a desempenho em textos e de contexto, que podem vir a apontar caminhos para a 
melhoria da qualidade do ensino, para a adequação de estratégias pedagógicas e de gestão, o que impacta indiretamente o fazer pedagógico nas escolas.

A seguir apresentamos o Quadro 04 que sistematiza a busca por referência ao SAEB pelo PNLD.

Quadro 4 - Referência ao SAEB pelo PNLD

\begin{tabular}{|l|l|l|}
\hline \multicolumn{1}{|c|}{ Item } & \multicolumn{1}{c|}{$\begin{array}{c}\text { Referência ao } \\
\text { SAEB }\end{array}$} & \multicolumn{1}{c|}{ Justificativa } \\
\hline Objetivo & Inexistente & Objetivo do PNLD não contem referência ao SAEB. \\
\hline Base legal & Inexistente & A legislação alusiva ao PNLD não faz referência ao SAEB. \\
\hline Homepage & Inexistente & A Homepage do PNLD não contém alusão ao SAEB. \\
\hline
\end{tabular}

Fonte: Site do FNDE/PNLD.

No quadro 04, é possível verificar que o PNLD, importante ação de política no que concerne fornecimento de material didático, não dialoga diretamente com as políticas do SAEB, apesar de se mostrarem políticas complementares, o que pode gerar um deslocamento do que é avaliado e entendido como importante na avaliação da educação básica e o material didático utilizado, levando a resultados não tão satisfatórios.

O Quadro 05 a seguir apresenta a sistematização dos resultados de uma busca de referências à Avaliação Externa nos editais do PNLD de 2007 a 2020. Para realizar a busca foram procurados com o auxílio da ferramenta "Localizar" nos editais do PNLD dos Anos Iniciais do Ensino Fundamental (AI), Anos Finais do Ensino Fundamental (AF) e Ensino Médio (EM) as expressões procuradas foram: SAEB, Avaliação de larga escala, Prova Brasil/ENEM e Avaliação Externa.

Quadro 5 - Referência a avaliação externa nos editais do PNLD de 2007 a 2020

\begin{tabular}{|c|c|c|c|c|c|}
\hline \multirow[b]{2}{*}{ Editais } & \multirow[b]{2}{*}{ Finalidade } & \multicolumn{4}{|c|}{ Ocorrências das Expressões procuradas } \\
\hline & & SAEB & $\begin{array}{l}\text { Avaliação de } \\
\text { larga escala }\end{array}$ & $\begin{array}{c}\text { Prova } \\
\text { Brasil/ENEM }\end{array}$ & $\begin{array}{c}\text { Avaliação } \\
\text { externa }\end{array}$ \\
\hline 2007 & Anos Iniciais & Não ocorreu & Não ocorreu & Não ocorreu & Não ocorreu \\
\hline 2008 & Anos Finais & Não ocorreu & Não ocorreu & Não ocorreu & Não ocorreu \\
\hline $2009 * * *$ & Ensino Médio & ----- & $\begin{array}{c}---- \\
\end{array}$ & $\begin{array}{c}---- \\
\end{array}$ & ----- \\
\hline 2010 & Anos Iniciais & Uma vez $^{(1)}$ & Não ocorreu & Não ocorreu & Não ocorreu \\
\hline 2011 & Anos Finais & Não ocorreu & Não ocorreu & Não ocorreu & Não ocorreu \\
\hline 2012 & Ensino Médio & Não ocorreu & Não ocorreu & Uma vez ${ }^{(2)}$ & Não ocorreu \\
\hline 2013 & Anos Iniciais & Não ocorreu & Não ocorreu & Não ocorreu & Não ocorreu \\
\hline 2014 & Anos Finais & Não ocorreu & Não ocorreu & Não ocorreu & Não ocorreu \\
\hline 2015 & Ensino Médio & Não ocorreu & Não ocorreu & Duas vezes $^{(3)}$ & Não ocorreu \\
\hline 2016 & Anos Iniciais & Não ocorreu & Não ocorreu & Não ocorreu & Não ocorreu \\
\hline 2017 & Anos Finais & Não ocorreu & Não ocorreu & Não ocorreu & Não ocorreu \\
\hline 2018 & Ensino Médio & Não ocorreu & Não ocorreu & Não ocorreu & Não ocorreu \\
\hline 2019 & Anos Iniciais & Duas vezes $^{(4)}$ & Não ocorreu & Uma vez ${ }^{(5)}$ & Não ocorreu \\
\hline 2020 & Anos Finais & Não ocorreu & Não ocorreu & Não ocorreu & Não ocorreu \\
\hline $2021 * * * *$ & Ensino Médio & Não ocorreu & Não ocorreu & Não ocorreu & Não ocorreu \\
\hline
\end{tabular}

Fonte: Site do FNDE/PNLD. 
Ao realizarmos a análise das informações organizadas no quadro 05 , verificamos que:

1. No edital do PNLD de 2010 para os anos iniciais ocorreu uma referência ao SAEB na página 38 com referência ao ensino da disciplina História.

2. No edital do PNLD de 2012 para o ensino médio ocorreu uma referência a Prova Brasil/ENEM na página 18 quando afirma que "Em consonância com a perspectiva apontada acima para o Ensino Médio, no âmbito do Exame Nacional do Ensino Médio (ENEM), mudanças se colocam no sentido de estabelecer os eixos cognitivos comuns a todas as áreas: (1) o domínio das linguagens tanto no que diz respeito à norma culta da Língua Portuguesa quanto ao uso das linguagens matemática, artística e científica e das línguas espanhola e inglesa; (2) a compreensão de fenômenos que se traduz na construção e aplicação de conceitos de várias áreas do conhecimento; (3) o enfrentamento de situações problema, por meio da seleção, organização, interpretação de dados e informações representados de diferentes formas; (4) a construção de argumentação, relacionando informações e conhecimentos disponíveis em situações concretas e (5) a elaboração de propostas de intervenção na realidade tendo por base os conhecimentos desenvolvidos na escola, o respeito aos valores humanos, levando em consideração a diversidade sociocultural. É nesse contexto que se insere o livro didático para o ensino médio, constituindo-se como mais uma ferramenta de apoio no desenvolvimento do processo educativo com vistas a assegurar tanto o trabalho com os eixos cognitivos comuns às áreas do conhecimento quanto a articulação entre ciência, cultura, trabalho e tecnologia nesta etapa da educação básica."

3. No edital do PNLD de 2015 para o ensino médio ocorreram duas referências a Prova Brasil/ENEM na página 37 quando afirma que "No entanto, o fato de esse jovem já ter concluído o ensino fundamental e, de além disso, poder manter-se nos estudos, mesmo quando já inserido no mercado de trabalho, lhe confere um status diferenciado. E o torna objeto de expectativas sociais específicas, a começar pelo papel de "indicador de qualificação" conferido à escolaridade média por toda uma gama de trabalhos, ofícios e profissões. Nesse sentido, aqueles conhecimentos que costumamos definir como "o essencial que um aluno de ensino médio deve saber" — objeto, por sua vez, de inquietações como as que se manifestam no ENEM e nos vestibulares - representam uma outra evidência do valor socialmente atribuído a esse nível de escolarização. ”. Também na página 39 quando repete integralmente o texto da página 18 do edital de 2012. 
4. No edital do PNLD de 2019 para os anos iniciais ocorreram duas referências a Prova Brasil/ENEM na página 4, no item referente aos itens de avaliação da Educação Básica, “as editoras que tiverem coleções aprovadas de Língua Portuguesa e Matemática (coleções disciplinares ou interdisciplinares) deverão entregar um conjunto de itens calibrados para constituição de um banco de itens do Ministério da Educação" é afirmado que "A quantidade máxima de itens corresponde a 1 item por descritor das Matrizes de Referência do Sistema de Avaliação da Educação Básica (Saeb) dos Anos Iniciais do Ensino Fundamental, que se aplicará ao editor que apresentar maior volume de vendas em cada um dos componentes." e na página 42 quando é informado que devem ser utilizadas "as matrizes de competências e habilidades do Saeb para língua portuguesa (somente leitura) e matemática para o $3^{\circ}$ e $5^{\circ}$ anos divulgadas pelo INEP." para a elaboração dos itens a serem doados. Também ocorreu uma referência a Prova Brasil na página 27 no item relativo as características e objetivos dos Anos Iniciais afirmando que "os processos tanto de letramento e alfabetização quanto de alfabetização matemática têm se revelado nucleares, dado o papel propedêutico que desempenham para toda a aprendizagem escolar. Em consequência, esses dois processos assumiram a dimensão de elementos orientadores, tanto nas reorganizações curriculares para o primeiro segmento, quanto na formação docente continuada1, ou mesmo em avaliações oficiais de rendimento, como a Avaliação Nacional da Alfabetização (ANA) e a Prova Brasil.”.

5. No edital do PNLD 2021 para o ensino Médio a expressão "exames de larga escala" foi encontrada sete vezes. Nas páginas 79, 81, 83, 85, 88, 91 e 93, páginas estas do ANEXO V do referido Edital sobre os critérios para a avaliação de obras didáticas. Todas as vezes que a referida expressão ocorre é localizada como exigência ao Manual do Professor apenas. A expressão em tela surge sempre após a seguinte afirmação: “O manual do professor deve apresentar de forma destacada os seguintes itens" quando um dos itens é "Diferentes propostas de avaliação condizentes com as características da obra didática por área de conhecimento [..], tanto de caráter formativo quanto de preparação para os exames de larga escala." A solicitação de questões do tipo avaliação de larga escala não é encontrada como exigência para o livro do estudante. Na página 11 do Edital em questão é informado que o edital referente aos Objetos Digitais de Aprendizagem, que terá edital publicado até 180 dias após a publicação do atual edital, que devem conter Itens de avaliação resolvidos e comentados para as seguintes Áreas do Conhecimento: Linguagens e suas Tecnologias, Língua Portuguesa, Língua Inglesa e Matemática e suas Tecnologias. 
Na página 12 do referido Edital há a previsão de uma Ferramenta On-line de Avaliação do Estudante que deve ter entre as suas funcionalidades "Banco de itens resolvidos e comentados sobre a BNCC do Ensino Médio”. Assim esse banco de questões será uma possibilidade ao estudante que tiver acesso aos recursos de informática, que na realidade brasileira está longe de estar disponível a maioria dos estudantes, principalmente aos estudantes que residem nos municípios mais distantes das capitais dos estados.

Um fato que merece destaque é que o edital de 2019 traz a seguinte exigência: "As editoras que tiverem coleções aprovadas de Língua Portuguesa e Matemática (coleções disciplinares ou interdisciplinares) deverão entregar um conjunto de itens calibrados para constituição de um banco de itens do Ministério da Educação; ”. Além disso, informa que "O conjunto de itens constitui contrapartida à compra do material impresso, não condicionando a aprovação da obra". Contudo, não traz a mesma exigência com própria ou similar condição em relação a presença de itens de avaliação de larga escala ao longo dos livros da coleção aprovada/submetida. Este fato, em nossa opinião, é mais um indicador da falta de diálogo entre o PNLD e o SAEB.

O próximo quadro apresenta a sistematização dos resultados de uma busca de referência à Avaliação Externa nos Guias do Livro didático de 2005 a 2018. A estratégia de procura e as expressões foram as mesmas utilizadas para buscar referências à Avaliação Externa nos editais do PNLD.

Quadro 6 - Referência a avaliação externa nos Guias do Livro didático de 2005 a 2018

\begin{tabular}{|c|c|c|c|c|c|}
\hline \multirow[b]{2}{*}{ Guia do ano } & \multirow[b]{2}{*}{ Disciplina } & \multicolumn{4}{|c|}{ Ocorrências das Expressões procuradas } \\
\hline & & SAEB & \begin{tabular}{l}
\multicolumn{2}{l}{ Avaliação } \\
de/em larga \\
escala
\end{tabular} & $\begin{array}{l}\text { Prova } \\
\text { /ENEM }\end{array}$ & $\begin{array}{l}\text { Avaliação } \\
\text { externa }\end{array}$ \\
\hline \multirow{3}{*}{$\begin{array}{l}2005 \\
\text { Anos Finais }\end{array}$} & Apresentação & Não ocorreu & Não ocorreu & Não ocorreu & Não ocorreu \\
\hline & Matemática & Não ocorreu & Não ocorreu & Não ocorreu & Não ocorreu \\
\hline & L. Portuguesa & Não ocorreu & Não ocorreu & Não ocorreu & Não ocorreu \\
\hline \multirow{3}{*}{$\begin{array}{l}2006 \\
\text { Ensino Médio }\end{array}$} & Apresentação* & $\begin{array}{ll}----- \\
\end{array}$ & ------ & $\begin{array}{ll}----- \\
\end{array}$ & ----- \\
\hline & Matemática & Não ocorreu & Não ocorreu & Não ocorreu & Não ocorreu \\
\hline & L. Portuguesa & Não ocorreu & Não ocorreu & Não ocorreu & Não ocorreu \\
\hline \multirow{3}{*}{$\begin{array}{l}2007 \\
\text { Anos Iniciais }\end{array}$} & Apresentação & Não ocorreu & Não ocorreu & Não ocorreu & Não ocorreu \\
\hline & Matemática & Não ocorreu & Não ocorreu & Não ocorreu & Não ocorreu \\
\hline & L. Portuguesa & Não ocorreu & Não ocorreu & Não ocorreu & Não ocorreu \\
\hline \multirow{3}{*}{$\begin{array}{l}2008 \\
\text { Anos Finais }\end{array}$} & Apresentação & Não ocorreu & Não ocorreu & Não ocorreu & Não ocorreu \\
\hline & Matemática & Não ocorreu & Não ocorreu & Não ocorreu & Não ocorreu \\
\hline & L. Portuguesa & Não ocorreu & Não ocorreu & Não ocorreu & Não ocorreu \\
\hline \multirow{3}{*}{$\begin{array}{l}2009 \\
\text { Ensino Médio }\end{array}$} & Apresentação & ----- & ----- & ----- & ----- \\
\hline & Matemática & Não ocorreu & Não ocorreu & Cinco vezes & Não ocorreu \\
\hline & L. Portuguesa & Não ocorreu & Não ocorreu & Quatro vezes & Não ocorreu \\
\hline \multirow{2}{*}{$\begin{array}{l}2010 \\
\text { Anos Iniciais }\end{array}$} & Apresentação & Não ocorreu & Não ocorreu & Não ocorreu & Não ocorreu \\
\hline & Matemática & Não ocorreu & Não ocorreu & Não ocorreu & Não ocorreu \\
\hline
\end{tabular}




\begin{tabular}{|c|c|c|c|c|c|}
\hline & L. Portuguesa & Não ocorreu & Não ocorreu & Não ocorreu & Não ocorreu \\
\hline \multirow{3}{*}{$\begin{array}{l}2011 \\
\text { Anos Finais }\end{array}$} & Apresentação & Não ocorreu & Não ocorreu & Não ocorreu & Não ocorreu \\
\hline & Matemática & Não ocorreu & Não ocorreu & Não ocorreu & Não ocorreu \\
\hline & L. Portuguesa & Não ocorreu & Não ocorreu & Não ocorreu & Não ocorreu \\
\hline \multirow{3}{*}{$\begin{array}{l}2012 \\
\text { Ensino Médio }\end{array}$} & Apresentação & Não ocorreu & Não ocorreu & Não ocorreu & Não ocorreu \\
\hline & Matemática & Não ocorreu & Não ocorreu & Doze vezes & Não ocorreu \\
\hline & L. Portuguesa & Não ocorreu & Não ocorreu & Dezessete vezes & Não ocorreu \\
\hline \multirow{3}{*}{$\begin{array}{l}2013 \\
\text { Anos Iniciais }\end{array}$} & Apresentação & Não ocorreu & Não ocorreu & Não ocorreu & Não ocorreu \\
\hline & Matemática & Três vezes & Não ocorreu & Uma vez & Não ocorreu \\
\hline & L. Portuguesa & Não ocorreu & Não ocorreu & Não ocorreu & Não ocorreu \\
\hline \multirow{3}{*}{$\begin{array}{l}2014 \\
\text { Anos Finais }\end{array}$} & Apresentação & Não ocorreu & Não ocorreu & Não ocorreu & Não ocorreu \\
\hline & Matemática & Não ocorreu & Não ocorreu & Não ocorreu & Não ocorreu \\
\hline & L. Portuguesa & Uma vez & Não ocorreu & Uma vez & Não ocorreu \\
\hline \multirow{3}{*}{$\begin{array}{l}2015 \\
\text { Ensino Médio }\end{array}$} & Apresentação & Não ocorreu & Não ocorreu & Não ocorreu & Não ocorreu \\
\hline & Matemática & Não ocorreu & Não ocorreu & Três vezes & Não ocorreu \\
\hline & L. Portuguesa & Não ocorreu & Não ocorreu & Treze vezes & Não ocorreu \\
\hline \multirow{3}{*}{$\begin{array}{l}2016 \\
\text { Anos Iniciais }\end{array}$} & Apresentação & Não ocorreu & Não ocorreu & Não ocorreu & Não ocorreu \\
\hline & Matemática & Não ocorreu & Não ocorreu & Não ocorreu & Não ocorreu \\
\hline & L. Portuguesa & Não ocorreu & Não ocorreu & Não ocorreu & Não ocorreu \\
\hline \multirow{3}{*}{$\begin{array}{l}2017 \\
\text { Finais }\end{array}$} & Apresentação & Não ocorreu & Não ocorreu & Não ocorreu & Não ocorreu \\
\hline & Matemática & Não ocorreu & Não ocorreu & Não ocorreu & Não ocorreu \\
\hline & L. Portuguesa & Não ocorreu & Não ocorreu & Não ocorreu & Não ocorreu \\
\hline \multirow{3}{*}{$\begin{array}{l}2018 \\
\text { Ensino Médio }\end{array}$} & Apresentação & Não ocorreu & Não ocorreu & Não ocorreu & Não ocorreu \\
\hline & Matemática & Não ocorreu & Não ocorreu & Quatro vezes & Não ocorreu \\
\hline & L. Portuguesa & Não ocorreu & Não ocorreu & Doze vezes & Não ocorreu \\
\hline \multirow{3}{*}{$\begin{array}{l}2019 \\
\text { Anos Iniciais }\end{array}$} & Apresentação & Não ocorreu & Não ocorreu & Não ocorreu & Não ocorreu \\
\hline & Matemática & Não ocorreu & Não ocorreu & Não ocorreu & Não ocorreu \\
\hline & L. Portuguesa & Não ocorreu & Não ocorreu & Não ocorreu & Não ocorreu \\
\hline
\end{tabular}

Fonte: Site do FNDE/PNLD

Ao analisarmos as informações apresentadas no quadro 06, podemos verificar que:

1. No Guia do Livro de Matemática do Ensino Médio de 2009 houve a ocorrência da expressão ENEM uma vez na página 38 quando informa que no final do terceiro livro da coleção Matemática Completa “encontram-se reproduzidas questões do ENEM, com respostas. ". Outra vez na página 51 quando informa que o terceiro volume da coleção Matemática no Ensino Médio "se encerra com questões do ENEM”. Novamente na página 57 quando é informado que a obra de volume único intitulada Matemática possui uma “Seção com questões do ENEM correspondentes ao período de 2000 a 2004.”. Mais uma vez na página 60 quando da análise do Livro do Professor é informado que "Ao final do livro, são apresentadas as questões do ENEM referentes ao período de 2000 a 2004.” A última vez na página 63 quando informa que a obra de volume único intitulada Matemática traz um anexo denominado "De Olho no ENEM."

2. No Guia do Livro de Língua Portuguesa do Ensino Médio de 2009 houve a ocorrência da expressão ENEM. Na página 40 quando foi informado que o livro do Professor da coleção Novas Palavras possui no bloco Gramática uma seção denominada Exercícios 
Complementares há "uma gama de atividades de revisão e verificação de aprendizagem. Alguns desses exercícios foram extraídos de concursos públicos diversos (como vestibulares e ENEM), para avaliação dos conteúdos estudados.”. Na página 50 quando foi informado que a Português Volume Único "é organizada em volume único, dividido em 47 unidades, constituídas, geralmente, das mesmas seções: Margens do texto, Horizontes do texto, Intertextualidade, Exame de textos, Literatura, Produção de textos e Gramática. As seções Exame de textos e Analisando e concluindo, esta apenas ao final de algumas unidades, reúnem questões de vestibulares e do ENEM, sobre Língua e Literatura.” A próxima ocorrência foi na página 59 , quando informado que em toda a terceira seção da obra: há questões selecionadas em exames de vestibulares de diversas instituições, ENEM e/ou MEC-Provão, que se destinam a "permitir a revisão dos conteúdos estudados" . A outra ocorrência foi na página 79 quando o Guia informa que em todas as seções denominadas Praticando da Coleção Português Ensino Médio "há questões de exames (vestibulares de diversas instituições brasileiras e ENEM)".

3. No Guia do Livro de Matemática de 2012. Ocorreu a expressão ENEM quatro vezes na página 40 na parte denominada de Características Gerais das Coleções Aprovadas do Guia quando foi afirmado: "É preciso ressaltar a excessiva inclusão de exercícios de concursos, vestibulares e do Enem. Tais exercícios estão disponíveis em outros meios e não precisariam ocupar tantas páginas dos livros didáticos. Além disso, ao distribuir exercícios do Enem, por exemplo, em listas propostas logo após a apresentação de um determinado tópico, desperdiça-se uma ocasião para desenvolver a principal habilidade para resolução de exercícios em concursos, que é identificar a que tópico e a que estratégia se pode recorrer para resolvê-lo.". Após esta edição do guia de matemática houve queda significativa da ocorrência da expressão ENEM nos Guias de matemática dos anos consecutivos. Valendo ressaltar que a consideração a respeito do excesso de questões do ENEM é novamente marcada na página 41 do documento. As demais ocorrências da expressão ENEM se deram em situações de apresentação de livros sem mais comentários.

4. No Guia do Livro de Língua Portuguesa do Ensino Médio de 2002 houve a ocorrência da expressão ENEM. Na página 9 da seção Língua Portuguesa no Contexto do Ensino Médio quando foi afirmado que "conhecimentos que costumamos definir como "o essencial que um aluno de EM deve saber" - objeto, por sua vez, de inquietações sociais como a que se manifesta no Enem e nos vestibulares — representa uma outra evidência do valor 
socialmente atribuído a esse nível de escolarização. ”E a demais ocorrências se deram ao longo das resenhas das obras avaliadas.

5. No Guia do Livro de Matemática de 2013, ocorreu a expressão SAEB nas páginas 56, 163 e 183 durante a descrição de obras avaliadas, sem comentário sobre pertinência ou preocupação com o referido sistema de avaliação. A expressão Prova Brasil ocorreu na página 183 durante a descrição de uma obra avaliada novamente sem maiores comentários.

6. No Guia do Livro de Língua Portuguesa dos Anos finais do Ensino Fundamental de 2014, a expressão SAEB ocorreu na página 26 na parte referentes as características das obras resenhadas, quando é informado que "Exploram-se significativamente capacidades leitoras focalizadas em exames nacionais de desempenho (Saeb e Enem, por exemplo) as obras resenhadas".

7. No Guia do Livro de Matemática do Ensino Médio de 2015, a expressão ENEM ocorreu duas vezes na página 30 e uma vez na página 37, durante a apresentação de resenha de livros sem mais comentários.

8. No Guia do Livro de Português do Ensino Médio de 2015, a expressão ENEM ocorreu três vezes na seção denominada "Escolhendo um Livro Didático de Língua Portuguesa- O Caminho das Pedras" e as demais ocorrências da expressão se deram nas resenhas das obras sem mais comentários.

9. No Guia do Livro de Matemática do Ensino Médio de 2018 a expressão ENEM ocorreu quatro vezes, sendo todas elas durante a apresentação de resenhas de obras analisadas sem mais comentários.

10. No Guia do Livro de Língua Portuguesa do Ensino Médio de 2018, houve a ocorrência da expressão ENEM doze vezes em trechos do documento que apresentavam resenhas de obras analisadas sem mais comentários.

A análise dos resultados supra apresentados indica que os Guias dos Livros Didáticos na maioria de suas edições não fezem referência ao SAEB, Prova Brasil, Avaliação de Larga Escala, Avaliação em Larga Escala ou Avaliação Externa e que houve momentos em que os autores dos Guias se posicionaram contrários a presença de questões do tipo utilizadas nos exames de larga escala, o que deve ter sido um fator a mais para a ausência de tais questões nos livros didáticos do PNLD.

Vejamos a seguir o Quadro 07 que apresenta a síntese da busca de referência ao PNLD pelo SAEB. 
Quadro 7 - Referência ao PNLD pelo SAEB

\begin{tabular}{|c|c|c|}
\hline Item & $\begin{array}{l}\text { Referência ao } \\
\text { PNLD }\end{array}$ & Justificativa \\
\hline Objetivo & Não há & $\begin{array}{l}\text { Objetivo do SAEB não contém referência ao PNLD ou livro } \\
\text { didático }\end{array}$ \\
\hline $\begin{array}{l}\text { Questionário } \\
\text { Estudante } 3^{\circ} \text { ano } \\
\text { do Ensino Médio } \\
2013, \quad 2015 \quad \text { e } \\
2017 .\end{array}$ & Não há & $\begin{array}{l}\text { O Questionário do Estudante do } 3^{\circ} \text { ano do Ensino Médio do } \\
\text { ano de } 2013 \text { traz dois itens sobre o livro didático. Um sobre o } \\
\text { uso do LD para realizar tarefas de casa de Língua Portuguesa } \\
\text { e outro sobre o uso do LD para realizar tarefas de casa de } \\
\text { matemática. } \\
\text { Os Questionários do Estudante do } 3^{\circ} \text { ano do Ensino Médio de } \\
2015 \text { e } 2017 \text { trazem a mesmas questões do respectivo } \\
\text { Questionário de } 2013 \text {. }\end{array}$ \\
\hline $\begin{array}{l}\text { Questionário } \\
\text { Estudante } 5^{\circ} \text { ano } \\
\text { do } \quad \text { Ensino } \\
\text { Fundamental } \\
2013,2015 \text { e } 2017\end{array}$ & Não há & $\begin{array}{l}\text { Os Questionários do Estudante do } 5^{\circ} \text { ano do Ensino } \\
\text { Fundamental de } 2013,2015 \text { e } 2017 \text { não trazem itens sobre o } \\
\text { livro didático. }\end{array}$ \\
\hline $\begin{array}{l}\text { Questionário } \\
\text { Estudante } 9^{\circ} \text { ano } \\
\text { do } \quad \text { Ensino } \\
\text { Fundamental } \\
2013,2015 \text { e } 2017\end{array}$ & Não há & $\begin{array}{l}\text { Os Questionários do Estudante do } 9^{\circ} \text { ano do Ensino } \\
\text { Fundamental de } 2013,2015 \text { e } 2017 \text { não trazem itens sobre o } \\
\text { livro didático. }\end{array}$ \\
\hline $\begin{array}{l}\text { Questionário } \\
\text { Docente } 2013\end{array}$ & Não há & $\begin{array}{l}\text { O Questionário do Docente de } 2013 \text { traz seis questões (97, 98, } \\
99,110,101 \text { e } 111 \text { ) que versam respectivamente sobre: a) } \\
\text { participação da escolha do LD, b) a concordância entre o LD } \\
\text { escolhido e o LD recebido c) a quantidade de LD em relação } \\
\text { a necessidade da escola, d) ao momento da chegada do LD em } \\
\text { relação ao início do período letivo, f) qualidade do livro } \\
\text { didático e g) uso do LD. As questões sobre o livro didático do } \\
\text { questionário não apresentam relação direta ou indireta com o } \\
\text { SAEB. } \\
\text { Os Questionários do Docente de } 2015 \text { e } 2017 \text { trazem as } \\
\text { mesmas questões do Questionário Docente de } 2013 \text {. }\end{array}$ \\
\hline $\begin{array}{l}\text { Questionário } \\
\text { Diretor }\end{array}$ & $\begin{array}{l}\text { Não há referência } \\
\text { direta ao PNLD }\end{array}$ & $\begin{array}{l}\text { O questionário do diretor de } 2013 \text { traz cinco questões sobre o } \\
\text { livro didático }(85,86,87,88 \text { e } 89) \text { que versam } \\
\text { respectivamente sobre o uso do guia do Livro Didático do } \\
\text { MEC para escolha do Livro Didático, forma da escolha do } \\
\text { livro didático, ao momento da chegada do LD em relação ao } \\
\text { início do período letivo, a quantidade de LD em relação a } \\
\text { necessidade da escola e relação entre LD escolhido e LD } \\
\text { recebido. } \\
\text { Os Questionários do Diretor de } 2015 \text { e } 2017 \text { trazem a mesmas } \\
\text { questões do questionário de } 2013 \text {. }\end{array}$ \\
\hline $\begin{array}{l}\text { As Matrizes de } \\
\text { referência } 3^{\circ} \text { ano } \\
\text { Ensino Médio de } \\
2013,2015 \text { e } 2017\end{array}$ & Não há & $\begin{array}{l}\text { As matrizes de referência do } 3^{\circ} \text { ano do Ensino Médio, de } \\
\text { Língua Portuguesa e Matemática, dos anos de } 2013,2015 \text { e } \\
2017 \text { não fazem menção ao PNLD ou ao livro didático }\end{array}$ \\
\hline $\begin{array}{l}\text { As Matrizes de } \\
\text { referência } 9^{\circ} \text { ano } \\
\text { Ensino } \\
\text { Fundamental de } \\
2013,2015 \text { e } 2017 \\
\end{array}$ & Não há & $\begin{array}{l}\text { As matrizes de referência do } 9^{\circ} \text { ano do Ensino Fundamental, } \\
\text { de Língua Portuguesa e Matemática, dos anos de 2013, } 2015 \\
\text { e } 2017 \text { não fazem menção ao PNLD ou ao livro didático }\end{array}$ \\
\hline $\begin{array}{l}\text { As Matrizes de } \\
\text { referência } 5^{\circ} \text { ano } \\
\text { Ensino } \\
\text { Fundamental de } \\
2013,2015 \text { e } 2017\end{array}$ & Não há & $\begin{array}{l}\text { As matrizes de referência do } 5^{\circ} \text { ano do Ensino Fundamental, } \\
\text { de Língua Portuguesa e Matemática, dos anos de } 2013,2015 \\
\text { e } 2017 \text { não fazem menção ao PNLD ou ao livro didático }\end{array}$ \\
\hline
\end{tabular}




\begin{tabular}{|l|l|l|}
\hline Prova Brasil 2013 & Não há & $\begin{array}{l}\text { O documento intitulado Prova Brasil 2013 não faz referência } \\
\text { ao PNLD e nem ao livro didático }\end{array}$ \\
\hline $\begin{array}{l}\text { Cartilha SAEB } \\
2017\end{array}$ & Não há & $\begin{array}{l}\text { O documento intitulado Cartilha SAEB 2017 não faz } \\
\text { referência ao PNLD e nem ao livro didático }\end{array}$ \\
\hline Base legal & Não há & Legislação do SAEB não faz referência ao PNLD. \\
\hline Homepage & Não há & Homepage do SAEB não faz referência ao PNLD. \\
\hline
\end{tabular}

Fonte: Homepage e micro dados do SAEB.

A análise do quadro anterior indica a não existência de dialogo referencial entre o SAEB e o PNLD.

Com base nos resultados obtidos foi possível vislumbrarmos a existência periódica de um processo de avaliação, de livros didáticos e aprendizagem realizados pelos PNLD e SAEB, respectivamente, que contém etapas bem definidas e que ocorrem de maneira sistematicamente organizada e com a repetição das mesmas etapas. Estas características do processo permitem perceber o que denominamos de Ciclo da Produção do Fracasso da Avaliação de Larga Escala (CPFALE) como sendo o processo desenvolvido pelas ações do PNLD e SAEB, sem dialogo, que resultam da produção dos resultados de baixo desempenho dos estudantes na avaliação em larga escala.

A percepção desta produção do fracasso da avaliação de larga escala só pode ser percebida quando consideramos as relações entre as ações do PNLD e SAEB simultaneamente. Do contrário, tem-se a falsa sensação de que cada política ocorre sem influência nos resultados da outra ficando a escola como a única culpada pelos desastrosos resultados sistematicamente divulgados pela mídia.

As ações desenvolvidas durante o referido ciclo estão descritas no quadro 08 a seguir.

Quadro 8 - Ciclo de Produção do Fracasso da Avaliação de Larga Escala

\begin{tabular}{|c|c|c|c|}
\hline MEC/SEB/FNDE & Escola/Professores & Escola/Estudantes & MEC/INEP/SAEB \\
\hline $\begin{array}{l}\text { Avalia o LD sem levar } \\
\text { em consideração os } \\
\text { descritores do SAEB }\end{array}$ & $\begin{array}{l}\text { Não são consultados } \\
\text { frequentemente sobre o } \\
\text { que pensam dos livros } \\
\text { didáticos } \\
\text { disponibilizados para } \\
\text { seleção. }\end{array}$ & $\begin{array}{l}\text { Não são consultados } \\
\text { frequentemente sobre o } \\
\text { que pensam dos livros } \\
\text { didáticos que recebem }\end{array}$ & $\begin{array}{l}\text { Determina os } \\
\text { descritores e matriz de } \\
\text { referência com base nos } \\
\text { PCN. }\end{array}$ \\
\hline $\begin{array}{l}\text { Recomenda os Livros } \\
\text { Didáticos. }\end{array}$ & $\begin{array}{l}\text { Selecionam os Livros } \\
\text { Didáticos. }\end{array}$ & ------------- & $\begin{array}{l}\text { Elabora teste com base } \\
\text { nos seus descritores e } \\
\text { matriz de referência } \\
\text { com tipos de questões } \\
\text { que normalmente não } \\
\text { constam dos livros } \\
\text { didáticos distribuídos } \\
\text { às escolas. }\end{array}$ \\
\hline 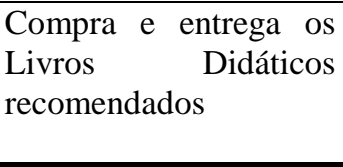 & $\begin{array}{lcr}\text { Utilizam } & \text { o } & \text { Livro } \\
\text { Didático, como recurso } & \\
\text { didático } & \text { recomendado } \\
\text { pelo } & \text { MEC, que não leva }\end{array}$ & $\begin{array}{l}\text { Estudam e resolvem } \\
\text { questões do Livro } \\
\text { Didático que são, quase } \\
\text { sempre, diferentes dos }\end{array}$ & --------------- \\
\hline
\end{tabular}




\begin{tabular}{|l|l|l|l|}
\hline & $\begin{array}{l}\text { em consideração a } \\
\text { matriz de referência do } \\
\text { SAEB no que diz } \\
\text { respeito aos tipos de } \\
\text { questões propostas. }\end{array}$ & $\begin{array}{l}\text { tipos solicitados na } \\
\text { prova Brasil. }\end{array}$ & \\
\hline------- & $\begin{array}{l}\text { Não participam do teste } \\
\text { e não recebem mais } \\
\text { informações sobre o } \\
\text { mesmo. }\end{array}$ & $\begin{array}{l}\text { Se submetem ao teste } \\
\text { elaborado pelo SAEB. }\end{array}$ & $\begin{array}{l}\text { Aplica o teste com a } \\
\text { participação de pessoas } \\
\text { desconhecidas dos } \\
\text { avaliados. }\end{array}$ \\
\hline Começa tudo de novo & $\begin{array}{l}\text { Levam a culpa sozinhos } \\
\text { pelos resultados que são } \\
\text { divulgados. }\end{array}$ & $\begin{array}{l}\text { A maioria fracassa no } \\
\text { teste }\end{array}$ & Divulga os resultados \\
\hline
\end{tabular}

Fonte: Os autores

A análise das ações desenvolvidas durante o CPFALE permite concluir:

1) O PNLD não seleciona livros didáticos que permitam os estudantes que os utilizem estejam preparados para realizar a Prova Brasil;

2) Os professores que utilizarem somente os livros didáticos recomendados pelo PNLD não conseguirão que seus estudantes tenham bom desempenho na Prova Brasil;

3) O processo de avaliação realizado pelo SAEB não atende as recomendações de Gatti (2003) sobre o processo de avaliação;

4) A responsabilização dos docentes é inadequada tendo em consideração que o material didático avaliado pelo Governo Federal por meio do PNLD não permite a devida preparação dos estudantes para os testes que são aplicados na avaliação de larga escala brasileira.

O ciclo de produção do fracasso da avaliação em larga escala é consequência da pouca articulação entre SAEB e PNLD, já que com a falta de diálogo entre os sistemas colocam a escola pública em uma situação permanente de tensão, na qual suas práticas pedagógicas voltadas para seu contexto específicas são modificadas para atender padrões com pouca significação para a comunidade escolar. 
Figura 1 - Representação da dinâmica das relações entre PNLD, Escola e SAEB

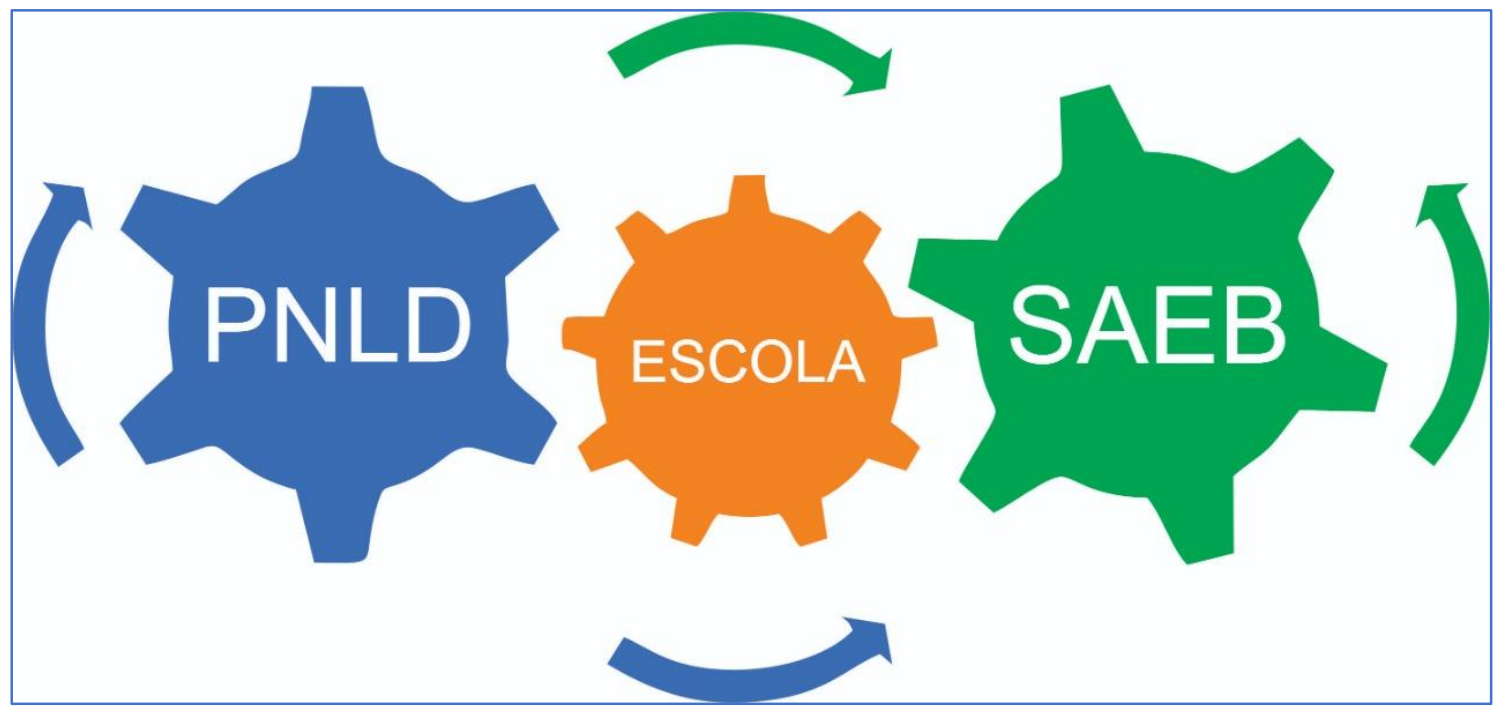

Fonte: os autores

A Figura 1 ilustra a tensão, pois coloca a escola no meio de movimentos contrários, o que não permite um funcionamento adequado das engrenagens.

\section{CONSIDERAÇões FinAIS}

Os resultados frutos da pesquisa realizada indicam que é necessária uma urgente revisão dos critérios de avaliação dos livros didáticos pelo FNDE para que os mesmos cumpram sua função básica e sirvam de base para ampliação dos conhecimentos dos estudantes e os auxiliem a terem êxito quando foram avaliados pela Prova Brasil. Além disso, ficou evidenciado a falta de diálogo referencial entre o SAEB e o PNLD que implica no desenvolvimento repetitivo do que denominamos de Ciclo de Produção do Fracasso da Avaliação de Larga Escala.

A falta de diálogo referencial traz consequências desastrosas, e entre elas podemos apontar: a produção de informações que não representam com fidelidade as atividades e nem espelham o trabalho desenvolvidos nas escolas, o que ocasiona: 1) maior desvalorização da escola pública diante da opinião da sociedade; 2) mudança infrutífera da forma de gestão da escola pública; 3) gasto de vultosas quantias de recursos oriundos da arrecadação dos inúmeros impostos aos quais o povo brasileiro é submetido cotidianamente, com livros didáticos que não tem condições de naturalmente preparar os estudantes para os exames de larga escala.

Com o objetivo de contribuir com a reflexão acerca do problema em tema sugerimos que inicialmente os professores da escola pública procurem preparar os seus estudantes para o exame em questão por meio da prática sistemática da resolução de questões com as mesmas características das questões do exame e da realização de simulados para que os estudantes, principalmente os do $5^{\circ}$ ano, se familiarizem com os comandos das questões, adquiram 
experiência de realizar as provas com tempo cronometrado de realização e ganhem habilidade na marcação de cartão resposta.

Também sugerimos que os professores, como legítimos representantes da área educacional do país façam solicitações formais ao MEC/FNDE para que os livros avaliados pelo PNLD passem a trazer questões do tipo Prova Brasil distribuídas ao longo das unidades dos livros didáticos em quantidade suficiente que permitam aos estudantes se prepararem naturalmente para o exame a partir da resolução de tais questões. Tal solicitação não poderá ser atendida até o ano de 2021, pois os editais do PNLD já foram publicados.

Ainda aludimos ser possível solicitar das Secretarias de Educação Estaduais e Municipais que sejam providenciadas coleções de questões com as características necessárias para permitir os estudantes um preparo adequado, ao longo dos seus estudos, para participar do evento não rotineiro que é a Prova Brasil/ ENEM e das avaliações próprias da cada rede de ensino, quando for o caso.

Não pretendemos aqui prescrever o que os professores devam ou não fazer nos processos pedagógicos, mas sim apontar a falta de diálogo e articulação entre o PNLD e o SAEB, especialmente no que concerne a preparação para a Prova Brasil, que pauta resultados que falham em traçar um panorama qualitativo da educação no Brasil, levando, assim, à desvalorização da escola pública.

Com relação à produção de informações sobre o desempenho dos estudantes avaliados, na oportunidade destacamos que da parte do SAEB deve haver a inclusão nos seus questionários ao docente e ao estudante de questões que permitam produzir avaliações sobre a qualidade do livro didático no que diz respeito a possibilidade de seu uso sistemático garantir condições aos estudantes de serem bem sucedidos nas avaliações externas. Cremos que uma das fontes de resultados de desempenho aquém do desejado está no fato do PNLD não solicitar aos autores que os livros produzidos tragam questões do tipo que são utilizadas nos exames de larga escala brasileiros, o que pode contribuir para o registro de desempenho abaixo do esperado como consequência de uma prática equivocada do ensino de um assunto numa direção, aprofundamento do mesmo em outra direção e avaliação do conteúdo ensinado com questões de formato totalmente diferentes do formato utilizado no aprofundamento do assunto, como foi registrado por Gatti (2003).

Por fim acreditamos que o estabelecimento de um real diálogo referencial entre o SAEB e o PNLD, em muito irá beneficiar a aprendizagem dos estudantes, elevar os percentuais de acertos nas avaliações em larga escala, aumentar a autoestima dos professores e dar mais 
visibilidade positiva sobre os benefícios e importância da Escola Pública como mediadora da mobilidade social de todos os cidadãos que dela precisam.

\section{REFERÊNCIAS}

ARAGÃO, Milena Ribeiro de.; FERREIRA, Renata Priscila Silva. SANTOS, Betisabel Vilar. Prova Brasil: instrumento de avaliação dos anos iniciais do Ensino fundamental. Cadernos de Graduação- Ciencias Humanas e Sociais. v.1, n.16, p. 103-114, 2013.

BAUER, Adriana. Estudos sobre Sistemas de Avaliação Educacional. Revista @mbienteeducação, São Paulo, v. 5, p. 7-31, 2012.

BAUER, Adriana. PIMENTA, Claudia Oliveira. HORTA NETO, João Luiz. SOUSA, Sandra Zákia Lian. Avaliação em larga escala em municípios brasileiros: o que dizem os números?

Est. Aval. Educ., São Paulo, v. 26, n. 62, p. 326-352, maio/ago. 2015

BRASIL. Ministério da Educação. Resultados do Índice de Desenvolvimento da Educação Básica - IDEB 2015. Brasília, 2016.

BRASIL. Guia de livros didáticos 2005: v. 1: Apresentação. Brasília: Ministério da Educação, Secretaria de Educação Infantil e Fundamental, 2004 a.20 p.

BRASIL. Guia de livros didáticos 2005: v. 2: Língua Portuguesa. Brasília: Ministério da Educação, Secretaria de Educação Infantil e Fundamental, 2004 b.287 p.

BRASIL. Guia de livros didáticos 2005: v.3: Matemática. Brasília: Ministério da Educação, Secretaria de Educação Infantil e Fundamental, 2004c. 212p.

BRASIL. Catalogo do Programa Nacional do Livro Didático para o Ensino Médio: PNLEM /2006: Lingua Portuguesa. Brasilia: MEC, SEMTEC, FNDE. 2005a. 100p.

BRASIL Catalogo do Programa Nacional do Livro Didático para o Ensino Médio:PNLEM/2006:Matemática. Brasilia: MEC, SEMTEC, FNDE.2005b. 84p.

BRASIL. Guia do livro didático 2007: apresentação: séries/anos iniciais do ensino fundamental. Brasília: Ministério da Educação, Secretaria de Educação Básica, 2006a. 44p.

BRASIL. Guia do livro didático 2007: Língua Portuguesa: séries/anos iniciais do ensino fundamental. Brasília: Ministério da Educação, Secretaria de Educação Básica, 2006b. 292p.

BRASIL. Guia do livro didático 2007: Matemática: séries/anos iniciais do ensino fundamental. Brasília: Ministério da Educação, Secretaria de Educação Básica,2006c. 266p.

BRASIL. Guia de livros didáticos PNLD 2008: apresentação. Brasília: Ministério da Educação. 2007a. 34p.

BRASIL. Guia de livros didáticos PNLD 2008: Língua Portuguesa. Brasília: Ministério da Educação. 2007b. 144p. 
BRASIL. Guia de livros didáticos PNLD 2008: Matemática. Brasília: Ministério da Educação. 2007c. 148p.

BRASIL. Língua Portuguesa: catálogo do Programa Nacional do Livro para o Ensino Médio: PNLEM/2009. Brasília: Ministério da Educação, Secretaria de Educação Básica, Fundo Nacional de Desenvolvimento da Educação., 2008a. 136 p.

BRASIL. Matemática: catálogo do Programa Nacional do Livro para o Ensino Médio: PNLEM/2009. Brasília: Ministério da Educação, Secretaria de Educação Básica, Fundo Nacional de Desenvolvimento da Educação, Fundo Nacional de Desenvolvimento da Educação. 2008b. 88 p

BRASIL. Guia de livros didáticos: PNLD 2010: apresentação. Brasília: Ministério da Educação, Secretaria de Educação Básica, 2009a. 52 p.

BRASIL. Guia de livros didáticos: PNLD 2010: Letramento e Alfabetização/ Língua Portuguesa. Brasília: Ministério da Educação, Secretaria de Educação Básica, 2009b. 352 p.

BRASIL. Guia de livros didáticos: PNLD 2010: Alfabetização Matemática e Matemática. Brasília: Ministério da Educação, Secretaria de Educação Básica, 2009c. 264 p.

BRASIL. Guia de livros didáticos: PNLD 2011: apresentação. Brasília: Ministério da Educação, Secretaria de Educação Básica, 2010a. 76 p.

BRASIL. Guia de livros didáticos: PNLD 2011: Língua Portuguesa. Brasília: Ministério da Educação, Secretaria de Educação Básica, 2010b. 76 p.

BRASIL. Guia de livros didáticos: PNLD 2011: matemática. Brasília: Ministério da Educação, Secretaria de Educação Básica, 2010c. 96 p.

BRASIL. Guia de livros didáticos: PNLD 2012: apresentação. Brasília: Ministério da Educação, Secretaria de Educação Básica, 2011a. 40 p.

BRASIL. Guia de livros didáticos: PNLD 2012: Língua Portuguesa. Brasília: Ministério da Educação, Secretaria de Educação Básica, 2011b.100 p.

BRASIL. Guia de livros didáticos: PNLD 2012: Matemática. Brasília: Ministério da Educação, Secretaria de Educação Básica, 2011c.104 p.

BRASIL. Guia de livros didáticos: PNLD 2013: apresentação. Brasília: Ministério da Educação, Secretaria de Educação Básica, 2012a. 40 p.

BRASIL. Guia de livros didáticos: PNLD 2013: Matemática. Brasília: Ministério da Educação, Secretaria de Educação Básica, 2012b. 252 p.

BRASIL. Guia de livros didáticos: PNLD 2013: letramento e alfabetização e língua portuguesa. Brasília: Ministério da Educação, Secretaria de Educação Básica, 2012c. 256 p.

BRASIL. Guia de livros didáticos: PNLD 2014: apresentação: ensino fundamental: anos finais. Brasília: Ministério da Educação, Secretaria de Educação Básica, 2013a. 40 p. 
BRASIL. Guia de livros didáticos: PNLD 2014: língua portuguesa: ensino fundamental: anos finais. Brasília: Ministério da Educação, Secretaria de Educação Básica, 2013b.120 p.

BRASIL. Guia de livros didáticos: PNLD 2014: matemática. Brasília: Ministério da Educação, Secretaria de Educação Básica, 2013c. 104 p.

BRASIL. Guia de livros didáticos: PNLD 2015: português: ensino médio. Brasília: Ministério da Educação, Secretaria de Educação Básica, 2014a. 104p.

BRASIL. Guia de livros didáticos: PNLD 2015: matemática: ensino médio. Brasília: Ministério da Educação, Secretaria de Educação Básica, 2014b. 108p.

BRASIL. Guia de livros didáticos: PNLD 2015: apresentação: ensino médio. Brasília: Ministério da Educação, Secretaria de Educação Básica, 2014c. 52p.

BRASIL. Guia de livros didáticos: PNLD 2016: Apresentação: ensino fundamental anos iniciais. Brasília: Ministério da Educação, Secretária de Educação Básica, 2015 a. 58 p.

BRASIL. Guia de livros didáticos: PNLD 2016: Alfabetização e Letramento e Língua

Portuguesa: ensino fundamental anos iniciais. Brasília: Ministério da Educação, Secretária de Educação Básica, 2015 b. 272p.

BRASIL. Guia de livros didáticos: PNLD 2016: Alfabetização Matemática e Matemática: ensino fundamental anos iniciais. Brasília: Ministério da Educação, Secretária de Educação Básica, 2015 c. 322p.

BRASIL. Ministério da Educação. PNLD 2019: Matemática - guia de livros didáticos. Brasília: Ministério da Educação, Secretária de Educação Básica, 2018a, 200 p.

BRASIL. Ministério da Educação. PNLD 2019: Língua Portuguesa -guia de livros didáticos. Brasília: Ministério da Educação, Secretária de Educação Básica, 2018b.236 p.

BRASIL. Ministério da Educação. PNLD 2019: Apresentação - guia de livros didáticos. Brasília: Ministério da Educação, Secretaria de Educação Básica, 2018c, 57 p.

BRASIL. PNLD 2017: apresentação - Ensino fundamental anos finais. Brasília: Ministério da Educação, Secretária de Educação Básica, Fundo Nacional de Desenvolvimento da Educação. 2016a. 39 p.

BRASIL. PNLD 2017: Língua Portuguesa- Ensino fundamental anos finais. Brasília: Ministério da Educação, Secretária de Educação Básica, Fundo Nacional de Desenvolvimento da Educação. 2016b. 98 p.

BRASIL. PNLD 2017: matemática - Ensino fundamental anos finais. Brasília: Ministério da Educação, Secretária de Educação Básica, Fundo Nacional de Desenvolvimento da Educação. 2016c. 155 p.

BRASIL. PNLD 2018: língua portuguesa - guia de livros didáticos - Ensino Médio: Ministério da Educação, Secretária de Educação Básica, Fundo Nacional de Desenvolvimento da Educação. 2017a. 109 p. 
BRASIL. PNLD 2018: matemática - guia de livros didáticos - Ensino Médio. Brasília: Ministério da Educação, Secretária de Educação Básica, Fundo Nacional de Desenvolvimento da Educação. 2017b. 122 p.

BRASIL. PNLD 2018: apresentação - guia de livros didáticos - ensino médio. Brasília: Ministério da Educação, Secretária de Educação Básica, Fundo Nacional de Desenvolvimento da Educação. 2017c. 39 p.

BRASIL. FNDE. Edital de convocação para inscrição no processo de avaliação e seleção de obras didáticas a serem incluídas no Guia de Livros Didáticos de $1^{\mathrm{a}}$ a $4^{\mathrm{a}}$ série do PNLD/2007, 2004.

BRASIL. FNDE. Edital de convocação para inscrição no processo de avaliação e seleção de obras didáticas a serem incluídas no Guia de Livros Didáticos dos anos finais do ensino fundamental do PNLD/2008, 2005.

BRASIL. FNDE. Edital de convocação para inscrição no processo de avaliação e seleção de obras didáticas para o programa nacional do livro didático -PNLD 2010, 2007.

BRASIL. FNDE. Edital de convocação para inscrição no processo de avaliação e seleção de coleções didáticas para o programa nacional do livro didático - PNLD 2011, 2008.

BRASIL. FNDE. Edital de convocação para inscrição no processo de avaliação e seleção de obras didáticas para o programa nacional do livro didático, PNLD 2012 - ENSINO MÉDIO, 2009.

BRASIL. FNDE. Edital de convocação para o processo de inscrição e avaliação de obras didáticas para o programa nacional do livro didático — PNLD 2013, 2010.

BRASIL. FNDE. Edital de convocação para o processo de inscrição e avaliação de coleções didáticas para o programa nacional do livro didático, PNLD 2014, 2011.

BRASIL. FNDE. Edital de convocação para o processo de inscrição e avaliação de obras didáticas para o programa nacional do livro didático, PNLD 2015, 2013.

BRASIL. FNDE. Edital de convocação para o processo de inscrição e avaliação de obras didáticas para o programa nacional do livro didático, PNLD 2016, 2014.

BRASIL. FNDE. Edital de convocação para o processo de inscrição e avaliação de obras didáticas para o programa nacional do livro didático, PNLD 2017, 2015.

BRASIL. FNDE. Edital de convocação para o processo de inscrição e avaliação de obras didáticas para o programa nacional do livro didático, PNLD 2018, 2015.

BRASIL. FNDE. Edital de Convocação para o processo de inscrição e avaliação de obras didáticas para o Programa Nacional do Livro e do Material Didático PNLD 2019, 2017d.

BRASIL. FNDE. Edital de convocação para o processo de inscrição e avaliação de obras didáticas e literárias para o programa nacional do livro e do material didático, PNLD 2020, 2018. 
BRASIL. FNDE. Edital de convocação para o processo de inscrição e avaliação de obras didáticas, literárias e recursos digitais para o programa nacional do livro e do material didático, PNLD 2021, 2019.

GATTI, Bernadete. O professor e a avaliação em sala de aula. Estudos em Avaliação Educacional, n. 27, p.98-114, jan-jun/2003

QUARTIERI, Marli Teresinha. GIONGO, Ieda Maria. REHFELDT, Márcia Jussara Hepp. SCHMITT, Fernanda Eloisa. ZIEGLER, Janaina de Ramos. Atividades presentes nos livros didáticos de matemática e questões da prova brasil: implicações para a prática pedagógica. Revista de Extensão, Santa Maria, v. 3, n. Especial, p. 616-621, 2016.

HORTA NETO, João Luiz. As avaliações externas e seus efeitos sobre as políticas educacionais: uma análise comparada entre a União e os Estados de Minas Gerais e São Paulo. Tese (Doutorado em Política Social) Universidade de Brasília 2013, 358p.

HORTA NETO, João Luiz. Avaliações Educacionais e seus reflexos em ações federais e na mídia eletrônica. Estudos em Avaliação Educacional, São Paulo, v. 25, n. 59, p. 172-201, set./dez. 2014.

MANTOVANI, Katia Paulilo. O Programa Nacional do Livro Didático-PNLD: impactos na qualidade do ensino público. Dissertação (Mestrado em Geografia Humana) USP, São Paulo 2009.

VIANNA, Heraldo Meriim . A Prática da Avaliação Educacional: algumas colocações metodológicas. Estudos em Avaliação Educacional, São Paulo, v. 25, n. 60, p. 178-195, n. especial, dez. 2014

VINHA, Luis Gustavo do Amaral. LAROS, Jacob Arie. Dados Ausentes em Avaliações Educacionais: comparação de métodos de tratamento. Estudos em Avaliação Educacional, São Paulo, v. 29, n. 70, p. 156-187, jan./abr. 2018.

SAMPAIO, Aline Feitosa. Fatores preditivos do desempenho de alunos na Prova Brasil: um estudo multínível. Dissertação (Mestrado em Psicologia). Universidade Federal da Bahia. Faculdade de Filosofia e Ciências Humanas, Salvador, 2014. 135 f.

SOUZA, Fábia Maria de. Campo, habitus, competências e práticas de ensino dos professores de Matemática de escolas brasileiras do ensino médio estadual com bons resultados no Enem. Tese (Doutorado em Engenharia de Produção) Universidade Federal de São Carlos. São Carlos, 2017, 307 p.

Recebido em: 12 de maio de 2020 .

Aprovado em: 14 de julho de 2020. 